Revista Latinoamericana de la Papa 19 (1): 40-58

ISSN: 1853-4961

http://www.papaslatinas.org/revista.html

\title{
Efecto de los bioinsumos sobre la capacidad de respuesta de cultivares nativos de papa (Solanum tuberosum L.) a sequia
}

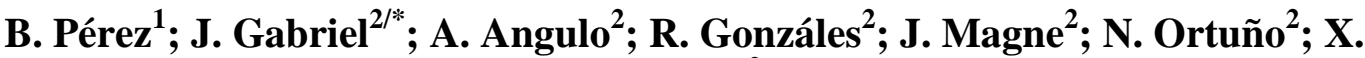 \\ Cadima $^{2}$
}

Manuscrito recibido: $21 / 11 / 2014$

Aceptado: 08/05/2015

Disponible en línea: Junio 2015

\section{Resumen}

En el año agrícola 2011-2012, con el objetivo de evaluar el efecto de los bioinsumos en la capacidad de respuesta a sequía, fueron sembrados 15 cultivares nativos de papa en un diseño experimental de bloques incompletos, con arreglo en parcelas divididas en franjas. Los factores fueron: Bioinsumo aplicado en la siembra (1= Gallinaza a razón de 10 t.ha ${ }^{-1}, 2=$

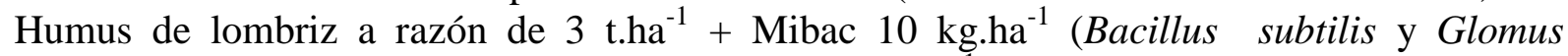
fasciculatum) y $3=$ Humus de lombriz a razón de $3 \mathrm{t}^{-h a^{-1}}$ ), Cultivar ( 15 cultivares nativos de papa: seis tetraploides y nueve diploides $)$ y Sequia $(1=\sin$ sequía y $2=$ con sequía: 37 días sin riego). Los resultados mostraron que la Gallinaza reduce la severidad e incrementa la recuperación y el rendimiento bajo sequia en mayor proporción $(\mathrm{P}<0,01)$ que el Humus de lombriz y el Humus de lombriz + Mibac (no significativo). Los cultivares Yana Sutamari (entre tetraploides) y Puka Taca (entre diploides) fueron los más resistentes, los que mejor recuperaron y mayores rendimientos obtuvieron bajo sequia. El análisis de correlación de Pearson mostró que para la Gallinaza las plantas con menor severidad recuperaron mejor $(\mathrm{P}<0,01)$. Para el Humus, las plantas con mayor contenido de clorofila fueron más resistentes a sequia $(\mathrm{P}<0,01)$ y para los tres bioinsumos en general, las plantas con mayor diámetro de tallo (más vigorosas) fueron más resistentes y obtuvieron mayores rendimientos bajo sequia $(\mathrm{P}<0,01)$.

Palabras claves adicionales: Resistencia, diploides, tetraploides, clorofila, Humus, Gallinaza.

\section{Summary \\ Bioinputs effect on response capability of potato landraces (Solanum tuberosum L.) to drought}

In agronomic season 2011-2012, in order to evaluate the bioinputs effect on drought response, 15 potato landraces were assessed along with control Waych'a in Kewiñal (Sacaba). The experimental design was the incomplete block design in strip plots arrangement. The factors were: Bioinputs applied during the Sown (1=Poultry manure in a dosis of 10 t.ha $^{-1}, 2=$

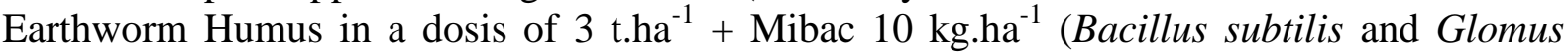
fasciculatum) and 3 = Earthworm Humus in a dosis of 3 t.ha ${ }^{-1}$ ), Cultivar (15 native potato cultivars: six tetraploids and nine diploids) and Drought $(1=$ without drought y 2 = drought: 37 days without watering). The results showed that the poultry manure reduced the drought severity and increased the recovery ability and yield under drought in higher amount $(\mathrm{P}<0,01)$ than the earthworm Humus $(\mathrm{P}<0,01)$ and the earthworm Humus + Mibac (not significant). Yana Sutamari (among tetraploids) and Puka Taca (among diploids) cultivars had the highest

\footnotetext{
Autor para correspondencia. Correo electrónico: j.gabriel@proinpa.org Universidad Pública de El Alto (UPEA), Casilla 13602, La Paz, Bolivia.

Fundación PROINPA, Casilla 4285, Cochabamba, Bolivia.
} 
resistance, the highest recovery degree and the highest yields under drought. The Pearson correlation analysis showed that for poultry manure, the plants with lower drought severities had higher recovery values $(\mathrm{P}<0,01)$. For Humus, the plants with higher chlorophyll contents were more drought resistant $(\mathrm{P}<0,01)$ and for all three bioinputs in general, the plants with thicker stem diameter (more vigorous) were more resistant and had higher yields under drought.

Keywords: Resistance, diploid, tetraploid, chlorophyll, Humus, poultry manure.

\section{Introducción}

La papa (Solanum tuberosum L.) es el cuarto cultivo sembrado, en más de cien países. La importancia de la papa radica en que sus tubérculos, que son parte de la dieta de millones de personas a nivel mundial, contienen $80 \%$ de agua y la materia seca está constituida por carbohidratos, proteínas, celulosa y minerales; además, son utilizadas en la industria para la producción de almidón (Ellisseche, 2000).

En Bolivia, la papa es típicamente cultivada en pequeñas superficies en las zonas altas e interandinas, en una superficie aproximada de 113.375 ha, representando la principal fuente de ingresos de 125.000 personas (Thiele et al., 2008). A pesar de la gran importancia que tiene en el país, la producción y productividad es baja, con un rendimiento promedio de 5.98 tha $^{-1}$ (Zeballos et al., 2009), aunque en los últimos años, han mejorado significativamente los rendimientos en algunas zonas de altura y de valles en Cochabamba y Santa Cruz. Entre las razones que explican esta situación, se encuentran la falta de agua de riego, suelos pobres en materia orgánica, cutivares con bajo potencial de rendimiento, semilla de baja calidad, cultivo en zonas montañosas que dificultan la mecanización, etc., pero además, se tiene la presencia de plagas, enfermedades, heladas, granizo y sequía (Gabriel et al., 2011).

El mayor rendimiento de papa a nivel mundial lo ostenta Nueva Zelanda con 47,5 tha ${ }^{-1}$ (FAO, 2012). En Bolivia los cultivares que más se producen son: Desirée (cultivada en sistema formal) con una superficie de 17.448 ha (15\%), Waych'a (S. andigena) con una superficie de 13.422 (12\%), Luki's (S. x juzepczukii y S. $x$ curtilobum) con 13.019 ha (11\%), Imilla Negra ( $S$. andigena) con 12.080 ha (11\%), Qoyllus (S. stenotomum) y otras nativas que ocupan 41.608 ha $(37 \%)$ (Torrez y Foronda, 2008; Thiele et al., 2008).

Se reconoce que en los andes de Bolivia, los agricultores aún conservan muchos cultivares nativos de las ocho especies conocidas, las mismas que son usadas para su alimentación y seguridad alimentaria. Sin embargo, poco se conoce acerca de los atributos de resistencia a los factores bióticos y abióticos que afectan a la papa y menos aun se han utilizado en los programas de mejora genética de papa en el mundo (Estrada, 2000; Gabriel, 2010).

Uno de los factores abióticos que más afecta en Bolivia es el estrés hídrico por sequía. El INE (2013) reportó 351 casos de sequía en el año 2002 y 651 casos en el año 2007. Así mismo, la misma fuente (INE, 2013) reportó 7.043 familias afectadas por la sequía en el año 2002 y 37.638 familias afectadas en el año 2007. Estos incrementos de casos y familias afectadas por sequía probablemente se deban a un cambio de clima. Por lo que la sequía es una limitante que ejerce el medio ambiente sobre la producción de papa en las áreas tradicionales de cultivo, influyendo en el desarrollo del mismo y 
causando pérdidas de rendimiento y calidad de tubérculos (Ekanayake, 1993).

Mamani (2000) encontró que el efecto de una sequía temprana (sequía pretuberización) ocasionaba tubérculos más pequeños tanto en cultivares sensibles como en tolerantes en referencia a una sequía tardía (sequía aplicada un mes después de la tuberización).

Miller y Martin (1987) encontraron que en un contexto de sequía muy marcada, la papa amarga Luki (S. $x$ juzepczukii) mostró un mejor comportamiento que la papa dulce Sani Imilla (S. andigena). Esta mejor adaptación a la sequía, es debida probablemente a un sistema radicular más desarrollado que le permite extraer con más fuerza el agua del suelo.

Ceccarelli (1984) menciona que para enfrentar el problema de sequia, existen dos alternativas: optimizar el uso de agua y/o generar cultivares genéticamente resistentes y/o tolerantes a sequia. La opción concerniente al manejo del agua se aplica específicamente para cultivos bajo riego. En cambio, para los suelos a secano, se contaría únicamente con la opción genética que permitiría lograr rendimientos estables en condiciones de ambientes contrastantes. Para la obtención de cultivares resistentes $\mathrm{y} / \mathrm{o}$ tolerantes a sequía se requiere del uso de germoplasma con estas características.

Asimismo, se ha reconocido la importancia del efecto de la materia orgánica en las propiedades físicas y químicas del suelo. Las propiedades influidas por la materia orgánica incluyen: la estructura del suelo, la capacidad de retención del agua, la diversidad y actividad de organismos del suelo (tanto beneficioso como dañino para la producción) y la disponibilidad de nutrientes. El incremento de materia orgánica en el suelo contribuye indirectamente a la porosidad del suelo (a través del incremento de la actividad de la fauna del suelo). De este modo el agua se infiltra más rápidamente y puede ser retenida en el suelo (Bot y Benites, 2005).

El estiércol puede incrementar el contenido de materia orgánica, el $\mathrm{pH}$, la capacidad de intercambio catiónico y el nivel de nutrientes de la planta. Asimismo, incrementa la capacidad de retención de humedad del suelo y la conductividad hidraúlica y el tamaño y cantidad de agregados hídro estables (Warren y Fonteno, 1994; Rojas y Ortuño, 2007). Por otra parte, el humus de lombriz posee una mayor capacidad de retención de humedad que un suelo sin materia orgánica y mayor población de microorganismos que el compost (Gajalakshmi y Abbasi, 2004, Rojas y Ortuño, 2007).

Un biofertilizante es una sustancia que contiene organismos vivos, los cuales cuando son aplicados ya sea la semila, a la planta o al suelo, colonizan la rizósfera o el interior de la planta y promueven el crecimiento a través del incremento de la provisión o disponibilidad de nutrientes primarios a la planta huésped. Se menciona por ejemplo que las micorrizas como el Glomus fasciculatum facilita la absorción de agua del suelo (Ortuño et al., 2010; Avilés et al., 2011). Por otra parte, las bacterias del tipo Bacillus, son promotores de crecimiento de la planta; que además las protegen de patógenos y permiten establecer una simbiosis haciendo que las plantas sean vigorosas $y$ de mayor rendimiento (Montecinos, 2011).

PROINPA conjuntamente con BIOTOP están trabajando en el desarrollo de bioinsumos que permitan mejorar la estructura del suelo y repoblar los suelos con microorganismos en simbiosis con las plantas (Avilés et al., 2011). El bioinsumo Mibac es un biofertilizante y promotor del crecimiento sólido en base a microorganismos nativos benéficos, Bacillus subtilis y micorrizas (Glomus spp.) Entre los beneficios de este biofertilizante en la reducción de los efectos de la sequia están: Mayor absorción de agua y tolerancia al estrés 
hídrico, agregación del suelo a través de la glomalina contenida en las hifas de las micorrizas, la liberación de nutrientes limitadamente disponibles en el suelo, la liberación de sustancias reguladoras del crecimiento de las plantas, tales como el ácido indol-3-acético (AIA) y el incremento de los rendimientos y la calidad del producto cosechado (Ortuño et al., 2011).

El objetivo de la investigación fue evaluar el efecto del estiércol de gallina, el humus de lombriz y el biofertilizante Mibac sobre la capacidad de respuesta de 14 cultivares nativos de papa a sequia en inicio de tuberización.

\section{Materiales y métodos}

La presente investigación se llevó cabo en la comunidad del Kewiñal del municipio de Sacaba en Cochabamba-Bolivia, ubicada a $17^{\circ} 20^{\prime} 10^{\prime \prime}$ latitud sur y $65^{\circ} 52^{\prime}$ 15" longitud oeste a $3.309 \mathrm{msnm}$, con temperatura promedio de $13,5{ }^{\circ} \mathrm{C}$, precipitación promedio 534,9 mm.año ${ }^{-1}$. La comunidad de Kewiñal corresponde a la zona Montañosa de Puna.

Se utilizó 14 cultivares nativos de papa (Tabla 1) de los cuales cuatro fueron locales (Cadima et al., 2004) y diez del Norte de Potosí (Terrazas et al., 2008). Se utilizó el cultivar Waych'a como testigo sistemático.

Tabla 1. Cultivares evaluados por su reacción al estrés hídrico por sequía y a la aplicación de bioinsumos. Año 2012.

\begin{tabular}{lccl}
\hline \multicolumn{1}{c}{ Cultivar } & Especie & Ploidía & Procedencia \\
\hline Yana Qoyllu & stn & $2 \mathrm{n}=2 \mathrm{x}=24$ & Candelaria, CBBA \\
Puca taca & stn & $2 \mathrm{n}=2 \mathrm{x}=24$ & Candelaria, CBBA \\
Pinta boca & stn & $2 \mathrm{n}=2 \mathrm{x}=24$ & Candelaria, CBBA \\
Candelero & stn & $2 \mathrm{n}=2 \mathrm{x}=24$ & Candelaria, CBBA \\
Imilla lunku & adg & $2 \mathrm{n}=4 \mathrm{x}=48$ & Norte Potosí, PO \\
Yana sutamari & adg & $2 \mathrm{n}=4 \mathrm{x}=48$ & Norte Potosí, PO \\
Puka sutamari & adg & $2 \mathrm{n}=4 \mathrm{x}=48$ & Norte Potosí, PO \\
Sakampaya & adg & $2 \mathrm{n}=4 \mathrm{x}=48$ & Norte Potosí, PO \\
Huaychu Qoyllu yana & stn & $2 \mathrm{n}=2 \mathrm{x}=24$ & Norte Potosí, PO \\
K'ellu zapallo & gon & $2 \mathrm{n}=2 \mathrm{x}=24$ & Norte Potosí, PO \\
Sani imilla & adg & $2 \mathrm{n}=4 \mathrm{x}=48$ & Norte Potosí, PO \\
Yana ajanhuiri & ajh & $2 \mathrm{n}=2 \mathrm{x}=24$ & Norte Potosí, PO \\
Yuraj ajanhuiri & ajh & $2 \mathrm{n}=2 \mathrm{x}=24$ & Norte Potosí, PO \\
Bola qoyllu & stn & $2 \mathrm{n}=2 \mathrm{x}=24$ & Norte Potosí, PO \\
Waych'a & adg & $2 \mathrm{n}=4 \mathrm{x}=48$ & CBBA \\
\hline
\end{tabular}

Leyendas: stn: Solanum stenotomum, gon: $S$. goniocalyx, ajh: $S . x$ ajanhuiri, adg: $S$. andigenum. CBBA: Cochabamba, PO: Potosí.

Fuente: Iriarte et al. (2009), Terrazas et al. (2008).

La siembra se realizó en octubre del 2011, los tubérculos fueron sembrados en surcos abiertos a una distancia de $0,30 \mathrm{~m}$ entre plantas y $0,70 \mathrm{~m}$ entre surcos. La superficie total de la parcela fue de $736 \mathrm{~m}^{2}$.

La parcela se implementó en un diseño de bloques incompletos (Siles, 2005) con arreglo en parcelas divididas en franjas, con cinco parcelas principales, tres bloques en cada parcela principal y 14 unidades experimentales en cada bloque. Los factores probados fueron: Factor A: 1=Gallinaza a razón de 10 t.ha ${ }^{-1}, 2=$ Humus de lombriz a razón de 3 t.ha ${ }^{-1}+$ Mibac 10 kg.ha ${ }^{-1}$ (Bacillus subtilis $\mathrm{y}$ Glomus fasciculatum), 3 = Humus de 
lombriz a razón de 3 t.ha ${ }^{-1}$ (Ortuño et al. 2011). Factor B: 1, 2, 3...15 cultivares nativos de papa y Factor C: 1 = sin sequía y 2 = con sequía (37 días $\sin$ riego).

El método de aplicación tanto de la gallinaza como del humus de lombriz fue de forma directa al surco; sin embargo, las micorrizas se aplicaron mediante la técnica de inoculación por aspersión a surco abierto sobre la semilla, como indica Ortuño et al. (2010).

En el desarrollo del cultivo se realizaron dos aporques, el primero en la emergencia, cuando las plántulas tuvieron una altura de $0,10 \mathrm{~m}$, el último aporque se realizó en la fase de llenado de tubérculo (170 días después de la siembra). Se hizo el deshierbe según el requerimiento del cultivo, y el manejo fue el mismo para todas las parcelas principales.

A los 50, 80 y 100 días después de la siembra se aplico el fungicida sistémico en base a Metalaxyl a razón de $0,2 \mathrm{~g}$ por $20 \mathrm{~L}$. de agua y Mancozeb a una dosis $60 \mathrm{cc}$ por $20 \mathrm{~L}$ de agua para el control preventivo del tizón de la papa (Phytophthora infestans) y la Alternaria sp. Además se aplicó un insecticida a base de clorpirifos y cipermetrina a una dosis de $13 \mathrm{~mL}$ por 20 L de agua para el control de la polilla (Symmetrischema tangolias).

Para aplicar el tratamiento de sequía, se construyeron carpas o túneles con estructuras de fierro y plástico, que se colocaron en cada unidad experimental a los 60 días después de la siembra (pre tuberización) durante 30 días. Estos túneles de plástico fueron destapados cuando no hubo precipitaciones. Para evitar la infiltración del agua de lluvia en las unidades experimentales con el tratamiento de sequía, se instalaron canales de drenaje revestidos con plástico.

A las unidades experimentales con riego se les suministro agua a capacidad de campo (CC) en una dosis de 500 L.ha $^{-1}$ siguiendo las etapas fenológicas de la papa
(Egúsquiza, 2000). El primer riego se realizó a los 30 días después de la emergencia (30 dde) en el estadío de crecimiento inicial con un volumen de agua de $25 \mathrm{~L} . h a^{-1}$, el segundo riego se realizó a los 45 dde (en el estadio de crecimiento lineal) con un volumen de agua de $75 \mathrm{~L} . h a^{-1}$, el tercer riego se realizó a los 55 dde (en el estadio de crecimiento lineal) con un volumen de agua de 100 L.ha ${ }^{-1}$, el cuarto riego se realizó a los 75 dde (en el estadio de pleno crecimiento) con un volumen de agua de 125 L.ha $^{-1}$ y finalmente el ultimo riego se realizó a 90 dde, en el estadio de madurez (tubérculos formados) con un volumen de 175 1.ha ${ }^{-1}$.

De igual manera se realizó un análisis del porcentaje de la materia orgánica y el $\mathrm{pH}$ de los diferentes en muestras de suelo con los diferentes factores evaluados (Factor A: 1=Gallinaza, $2=$ Humus de lombriz + Mibac y $3=$ Humus de lombriz).

Antes de iniciar el tratamiento de sequía se determinó el porcentaje de humedad del suelo mediante el método gravimétrico (Radulovich, 2009), los muestreos de suelo se hicieron tanto en las parcelas con riego y sin riego (uno antes, tres durante y uno después del tratamiento). En cada muestreo se obtuvieron muestras de suelo de cada tratamiento con tres repeticiones. $\mathrm{La}$ profundidad de muestreo fue de $0,30 \mathrm{~m} \mathrm{y}$ se realizó con cilindros de fierro de volumen conocido. Las muestras de suelo fueron llevadas a laboratorio para obtener el peso inicial y después fueron sometidas a un secado en un horno mufla a $110^{\circ} \mathrm{C}$ por 24 horas (hasta obtener peso constante), luego del cual se obtuvo el peso final. El porcentaje de humedad se calculó por la diferencia entre el peso inicial y el peso final.

Las variables de respuesta evaluadas en el estudio fueron: Severidad o grado de marchitez (GM), evaluada según la escala de Blum (1993) adaptada por Angulo et al. (2009); la capacidad de recuperación (CR), que se evaluó de acuerdo a la escala modificada para recuperación (Gabriel et 
al. 2011); el contenido de clorofila (CC), que se midió con el medidor de clorofila SPAD-520 en tres hojas de la parte media de la planta después de la sequia (Gonzáles, 2009); días a la floración (DF) evaluado al $50 \%$ de floración de la parcela, cobertura foliar (CF), que se evaluó mediante imágenes fotográficas después de la sequia, las mismas que se importaron al programa Cob Cal v.1, para calcular el porcentaje foliar (Ferrari et al., 2007), la materia seca de follaje (MSF) y de raíz (MSR) que se calcularon como cocientes del peso seco sobre el peso fresco, la altura de planta (AP), que se evaluó en cm desde el cuello de la planta hasta el ápice; el diámetro de tallo (DT), se evaluó con la ayuda de un vernier en $\mathrm{mm}$ en la parte más gruesa de la planta; largo de raíz (LR), que se evaluó en un perfil cultural no destructivo; el volumen de raíz (VR), que se determinó con una probeta de $500 \mathrm{~mL}$ en cinco plantas al azar después de la cosecha, el número de tubérculos (NT) y el rendimiento $(Y)$ en t.ha ${ }^{-1}$.

Los datos de cada una de las variables de respuesta que satisficieron o aproximaron a los supuestos de distribución normal y homogeneidad de varianzas, se analizaron

\section{Resultados}

En la Tabla 2 se observa el perfil del contenido de humedad del suelo a lo largo del tratamiento de sequia. Al inicio, tanto la parcela con sequia y sin sequia tuvieron un promedio de $23 \%$ de humedad de suelo, en la segunda lectura (durante la sequia) las parcelas sin sequia tuvieron una humedad promedio de suelo de $45 \%$, en cambio las parcelas con sequía tuvieron una humedad promedio de $22 \%$, en la tercera lectura (durante la sequia) las parcelas sin sequia tuvieron una humedad promedio de suelo de $51 \%$, en cambio las parcelas con sequía tuvieron una humedad promedio de $15 \%$, en la cuarta (último día de acuerdo a los modelos estadísticos planteados (Martínez-Garza, 1988).

Sobre la base del modelo mencionado, se realizaron análisis de varianza para probar hipótesis acerca de los efectos fijos y comparaciones de medias mediante contrastes de un grado de libertad, para determinar los cultivares más resistentes y/o que mejor recuperaron y/o rindieron bajo sequia y el mejor bioinsumo bajo sequia. El análisis de varianza también sirvió para estimar los componentes de varianza para los efectos aleatorios. Los análisis indicados se realizaron utilizando los Proc GLM y Mixed del SAS (SAS, 2004).

También se realizó un análisis de correlación entre el GM, la CR, el Y y las demás variables evaluadas para determinar el grado y tipo de asociación entre la resistencia, la capacidad de recuperación y el rendimiento bajo sequia con las demás variables evaluadas bajo sequia mediante el proc corr del SAS (SAS, 2004). El análisis de correlación se realizó para cada bioinsumo bajo tratamiento de sequia, esto con el propósito de observar las diferencias en el grado y tipo de asociación entre las variables evaluadas bajo sequia para cada bioinsumo.

de la sequia) lectura las parcelas sin sequia tuvieron una humedad promedio de suelo de $64 \%$, en cambio las parcelas con sequía tuvieron una humedad promedio de $18 \%$, en la quinta lectura (después de la sequia) que se realizó tres días después del riego de recuperación, las parcelas sin sequia tuvieron una humedad promedio de suelo de $68 \%$; en cambio las parcelas con sequía tuvieron una humedad promedio de $52 \%$. $\mathrm{Se}$ debe mencionar que entre los bioinsumos (gallinaza, humus, humus + micorriza) no hubieron diferencias en el procentaje de la humedad de suelo. De igual manera se observó que el porcentaje de materia orgánica fue alta y estuvo en un rango de $9,06 \%$ a $11,07 \%$ para todos $\operatorname{los}$ 
factores evaluados y el pH del suelo abrió

entre

5,4

a

6,8 .

Tabla 2. Porcentaje de humedad del suelo para el Factor A (gallinaza, humus y humus + micorriza) y el factor B (con sequía y sin sequia) antes, entre y después del tratamiento de sequia.

\begin{tabular}{llccccc}
\hline \multirow{2}{*}{ Factor A } & Factor B & \multicolumn{5}{c}{ Fechas de lecturas del porcentaje de humedad de suelo } \\
\cline { 3 - 7 } & & $\mathbf{1}$ & $\mathbf{2}$ & $\mathbf{3}$ & $\mathbf{4}$ & $\mathbf{5}$ \\
\hline \multirow{2}{*}{ Gallinaza } & Riego & 24,33 & 48,00 & 58,00 & 66,00 & 69,00 \\
& Sequia & 24,33 & 23,00 & 13,67 & 15,33 & 50,00 \\
\multirow{2}{*}{ Humus } & Riego & 20,67 & 38,67 & 40,33 & 56,67 & 66,00 \\
& Sequia & 20,67 & 22,00 & 17,00 & 14,00 & 52,67 \\
\multirow{2}{*}{ Humus + Micorriza } & Riego & 25,00 & 48,00 & 55,67 & 69,33 & 68,00 \\
& Sequia & 25,00 & 22,00 & 14,33 & 24,67 & 52,00 \\
\hline Promedio riego & & 23,33 & 44,89 & 51,33 & 64,00 & 67,67 \\
\hline Promedio sequia & & 23,33 & 22,33 & 15,00 & 18,00 & 51,56 \\
\hline
\end{tabular}

Lectura 1: 26/12/2011, 2: 12/01/2012, 3:26/01/2012, 4:02/02/2012, 5: 05/02/2012.

Los Coeficientes de Variación (C.V.) estuvieron entre 17 a $24 \%$ y son apropiados para este tipo de experimentos en campo. El $\mathrm{R}^{2}$ fue mayor a $90 \%$, lo que está indicando que hubo un alto ajuste de los datos al modelo empleado y que menos del $10 \%$ de la variabilidad observada son debidos a efectos ambientales (Tabla 3).

Tabla 3. Análisis de varianza (ANVA) para severidad (GM), capacidad de recuperación (CR) y rendimiento $(\mathrm{Y})\left(\mathrm{t}_{\mathrm{h}} \mathrm{h}^{-1}\right)$ en cultivares nativos sometidos a estrés hídrico por sequía y reacción a la aplicación de bioinsumos. Año 2012.

\begin{tabular}{|c|c|c|c|c|c|c|c|}
\hline \multirow[t]{2}{*}{ F.V. } & \multirow[t]{2}{*}{ Gl } & \multicolumn{2}{|c|}{ GM } & \multicolumn{2}{|c|}{$\mathbf{C R}$} & \multicolumn{2}{|c|}{$Y\left(\right.$ t.ha $\left.^{-1}\right)$} \\
\hline & & C.M. & $\sigma^{2}$ & C.M. & $\sigma^{2}$ & C.M. & $\sigma^{2}$ \\
\hline Blq & 2 & & 0 & & 0 & & 0 \\
\hline Sequia & 1 & $4,574 *$ & & $86,291 * *$ & & $1,502 * *$ & \\
\hline Blq*Sequia & 2 & & 0,004 & & 0 & & 0 \\
\hline Bioinsumo (Bio) & 2 & $0,342 * *$ & & $2,082^{*}$ & & $6,447 * *$ & \\
\hline Blq*Bio & & & 0 & & 0 & 0,191 & \\
\hline Cultivar (Cult) & 14 & $0,086^{* *}$ & & $1,226^{*}$ & & $0,937 * *$ & \\
\hline Bio*Sequia & 2 & $0,342 * *$ & & $2,082^{*}$ & & 0,042 & \\
\hline Cult*Sequia & 14 & $0,086^{* *}$ & & $1,226^{*}$ & & 0,033 & \\
\hline Cult*Bio & 28 & 0,020 & & 0,652 & & 0,194 & \\
\hline Cult*Sequia*Bio & 28 & 0,020 & & 0,652 & & 0,024 & \\
\hline Error & 32 & & 0,011 & & 0,460 & & 0,157 \\
\hline C.V. & & 17,787 & & 16,729 & & 23,704 & \\
\hline 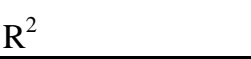 & & 0,968 & & 0,922 & & 0,916 & \\
\hline
\end{tabular}

El análisis de varianza (Tabla 3) mostró diferencias significativas $(\mathrm{P}<0,05)$ para sequia, lo cual significa que la sequia impuesta causó severidad $(0,83)$. 
Por otra parte, también existieron diferencias altamente significativas $(p<0,01)$ entre bioinsumos para severidad (Tabla 3). Las severidades obtenidas con Gallinaza $(0,53)$ y con el bioinsumo Humus + Mibac $(0,61)$ fueron inferiores a la obtenida con el bioinsumo Humus $(1,47)$ (Figura 1). Esto significa que los bioinsumos Gallinaza y Humus + Mibac ayudaron a las plantas a resistir mejor los efectos de la sequia.

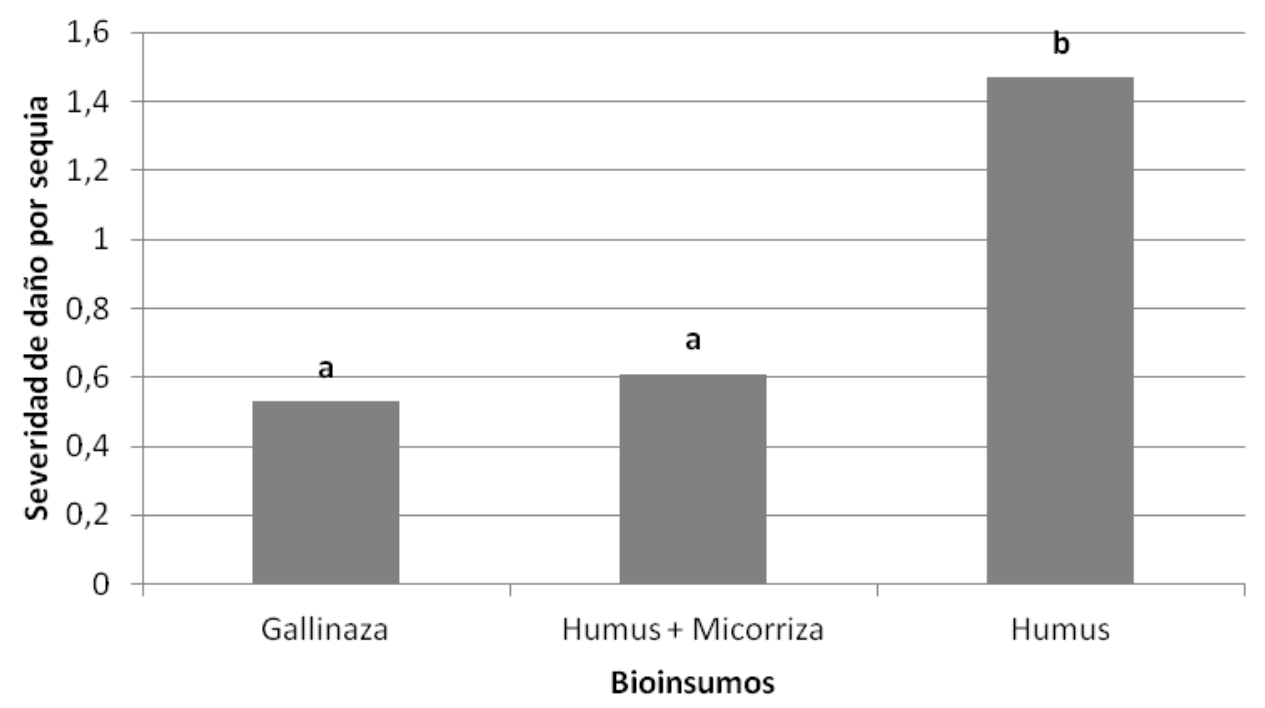

Figura 1. Respuesta del grado de severidad (GM) en 15 cultivares nativos de papa sometidos a sequía, en los que se aplicó tres bioinsumos. Año 2012. Las medias con la misma letra son estadísticamente iguales entre sí $(\mathrm{P}<0,01)$.

No hubo interacción Bioinsumo*cultivar $(\mathrm{p}=0,07)$ (Tabla 3), lo cual significa que el efecto de cada bioinsumo fue el mismo en la mayoría de los cultivares, como se observa en la Figura 2, esto debido probablemente a que las diferencias de las medias son pequeñas y no son detectadas por el análisis. 


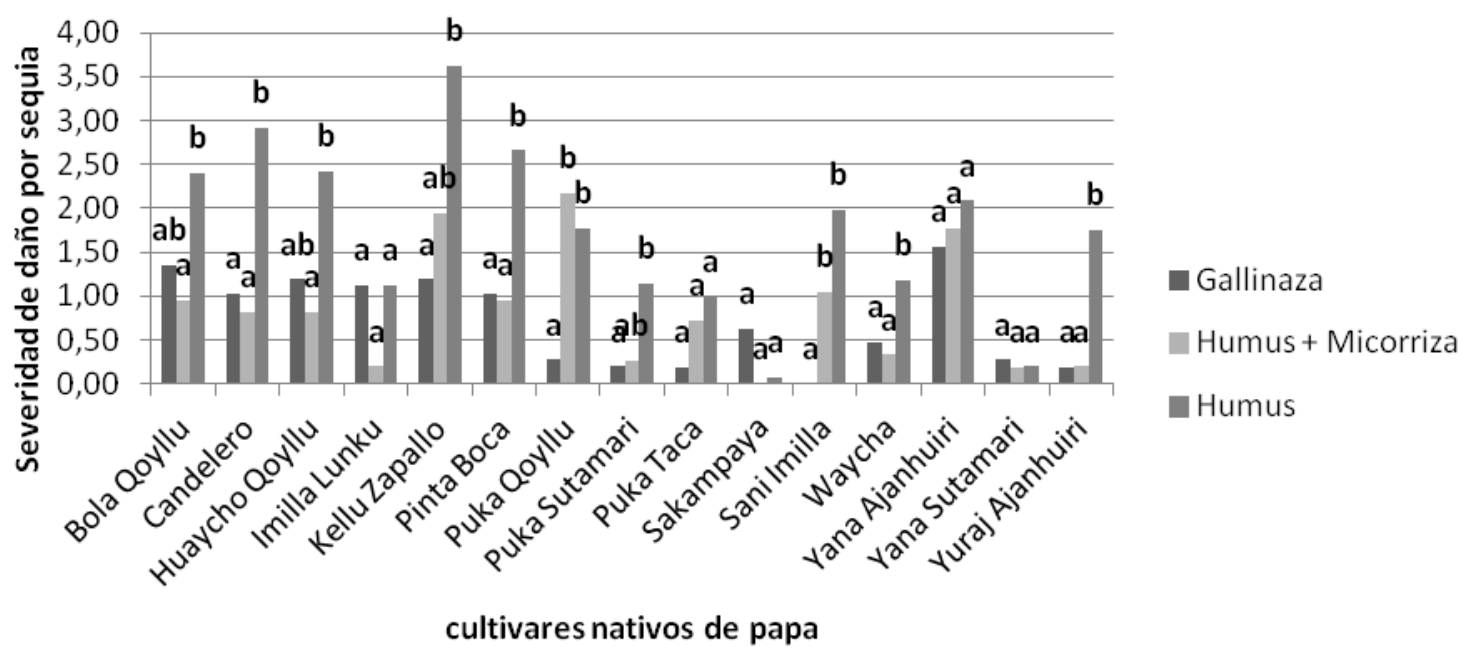

Figura 2. Respuesta del grado de severidad (GM) en 15 cultivares nativos de papa en los que se aplicó tres tratamientos de bioinsumos. Año 2012. Las medias con la misma letra son estadísticamente iguales entre sí $(\mathrm{P}<0,01)$.

Por otra parte, se observaron diferencias altamente significativas $(\mathrm{P}<0,01)$ entre cultivares para severidad, lo que indicó que al menos uno de los cultivares obtuvo un grado de severidad diferente a los demás cultivares. Cuando se realizaron las comparaciones de medias para las severidades de cada cultivar bajo sequia, se observó que los cultivares Sakampaya y Yana Sutamari (adg) (severidades $<0,1)$ fueron más resistentes que los cultivares Waych'a (adg), Imilla Lunku (adg), Sani Imilla (adg), Puka Qoyllu (stn), Huaycho Qoyllu (stn), Pinta Boca (stn), Candelero (stn), Bola Qoyllu (stn), Yana Ajanhuiri (ajh) y Kellu Zapallo (gon) (severidades $\geq$ 0,5) (Figura 3). Puka Sutamari (adg), Yana Ajanhuiri (ajh) y Puka Taca (stn) mostraron resistencia moderada a la sequía (severidades $>0,1$ y $<0,5$ ).

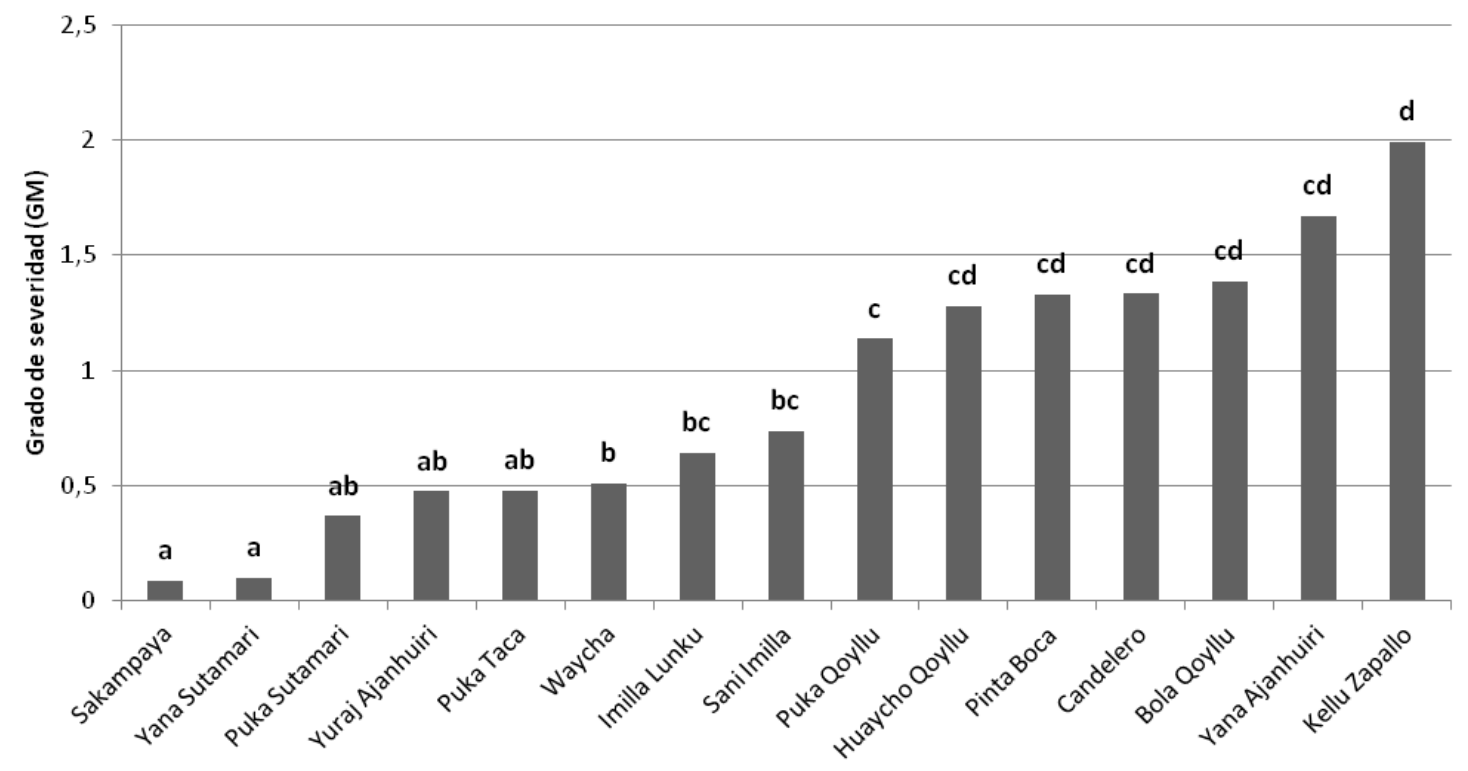

Figura 3. Respuesta del grado de severidad (GM) en 15 cultivares nativos sometidos a sequia, en los que se aplicó tres tratamientos de bioinsumos. Año 2012. Las medias con la misma letra son estadísticamente iguales entre sí $(\mathrm{P}<0,01)$. 
Revista Latinoamericana de la Papa 19 (1): 40-58

http://www.papaslatinas.org/revista.html

Para el grado de recuperación (Tabla 3) se observó diferencias significativas para bioinsumo $(\mathrm{P}<0,05)$. Con la Gallinaza (Figura 4) se obtuvo una mejor recuperación $(3,58)$ que con el Humus $(2,56)$. Sin embargo, con el Humus + Mibac el grado de recuperación $(3,15)$ fue el mismo que con Gallinaza y Humus.

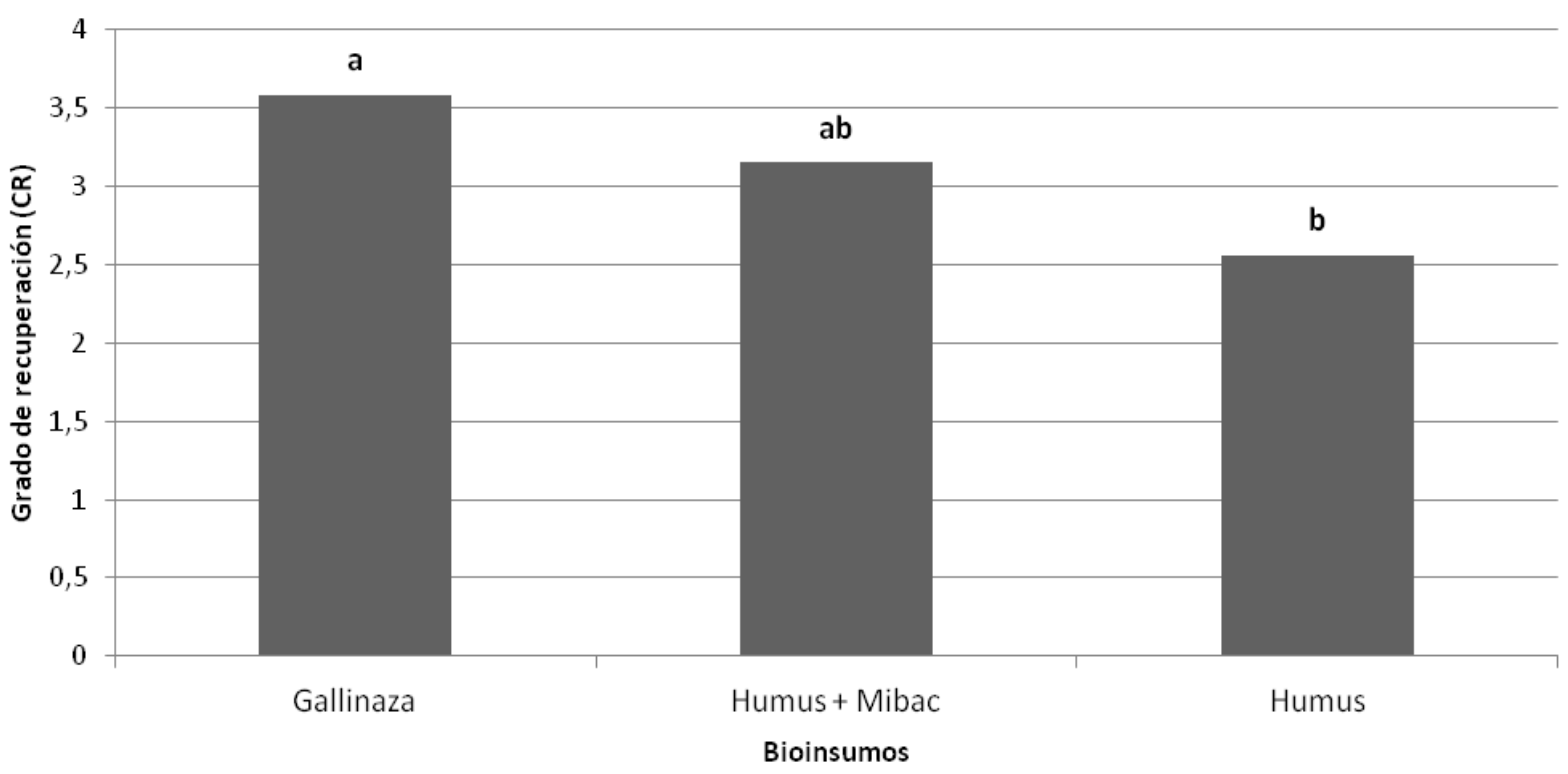

Figura 4. Respuesta del grado de recuperación (CR) de 15 cultivares nativos de papa sometidos a sequía, en los que se aplicó tres bioinsumos. Año 2012. Las medias con la misma letra son estadísticamente iguales entre sí $(\mathrm{P}<0,01)$.

Asimismo, se observó que existieron diferencias altamente significativas $(\mathrm{P}<0,01)$ para cultivar. No existió interaccion cultivar * bioinsumo $(\mathrm{P}=0,16)$ lo que indicó que el efecto de cada bioinsumo en el grado de recuperación fue el mismo para todos los cultivares (Figura 5). En la Figura 5 se compararon las medias de recuperación de los tres bioinsumo para cada cultivar. Cuando se realizaron las comparaciones de medias entre cultivares bajo sequia después del riego de recuperación (Figura 6), se observó que el cultivar que mejor recuperó fue Yana Sutamari (adg) (Grado de recuperación=5,0). En cambio, las que menos recuperaron fueron Puka Taca (stn), Yuraj Ajanhuiri (ajh), Waych'a (adg), Bola Qoyllu (stn), Pinta Boca (stn), Puka Sutamari (adg), Kellu Zapallo (gon), Candelero (stn), Imilla Lunku (adg), Puka Qoyllu (stn) y Yana Ajanhuiri (ajh) (Grados de recuperación $\geq 3,3$ ). Sakampaya (adg), Sani Imilla (adg) y Huaycho Qoyllu (stn) obtuvieron grados de recuperación intermedios (Grados de recuperación <4,3 $y>3,7)$. 


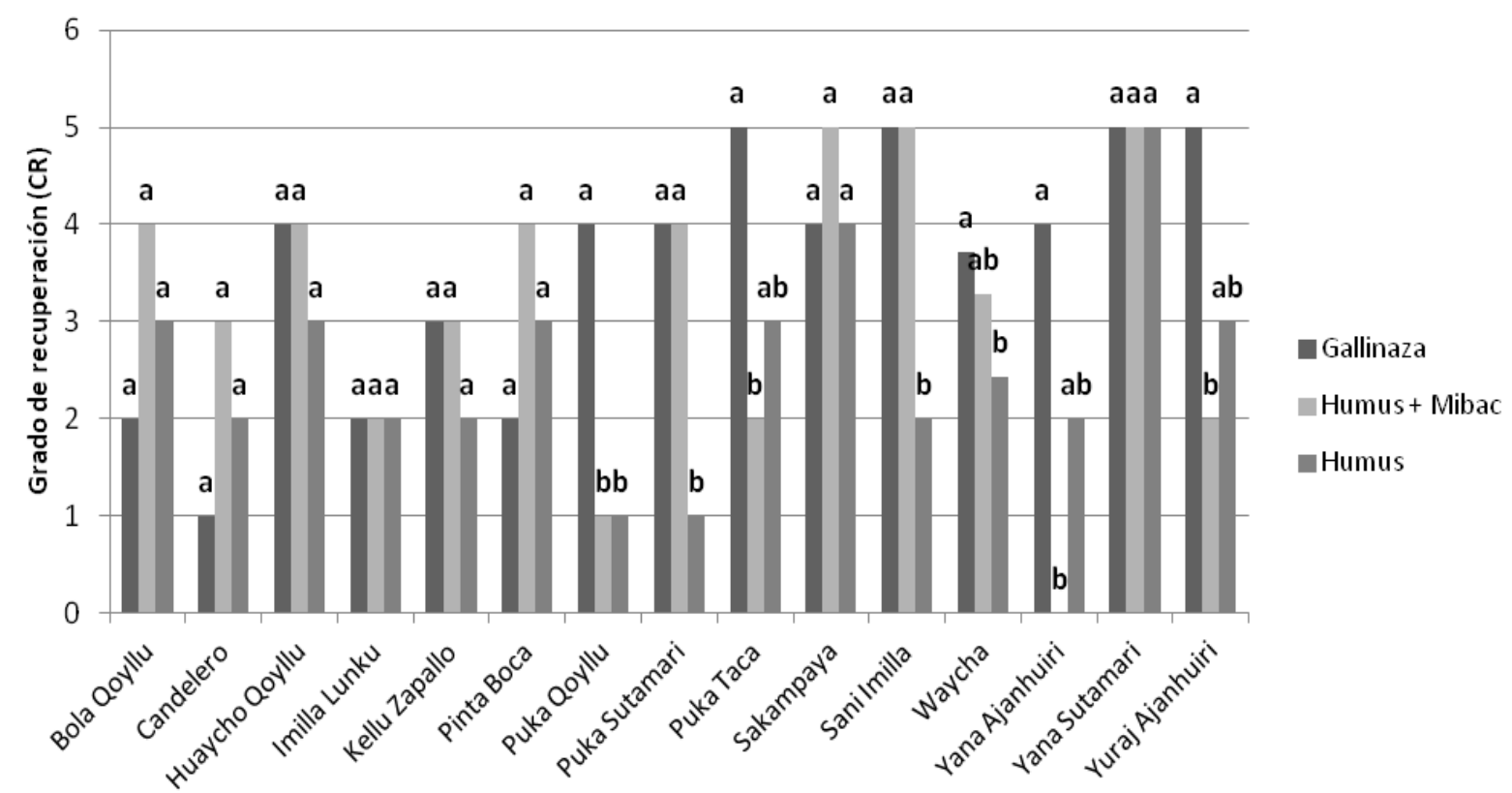

Figura 5. Respuesta del grado de recuperación (GR) en 15 cultivares nativos de papa sometidos a sequía, en los que se aplicó tres bioinsumos. Año 2012. Las medias con la misma letra son estadísticamente iguales entre sí $(\mathrm{P}<0,01)$.

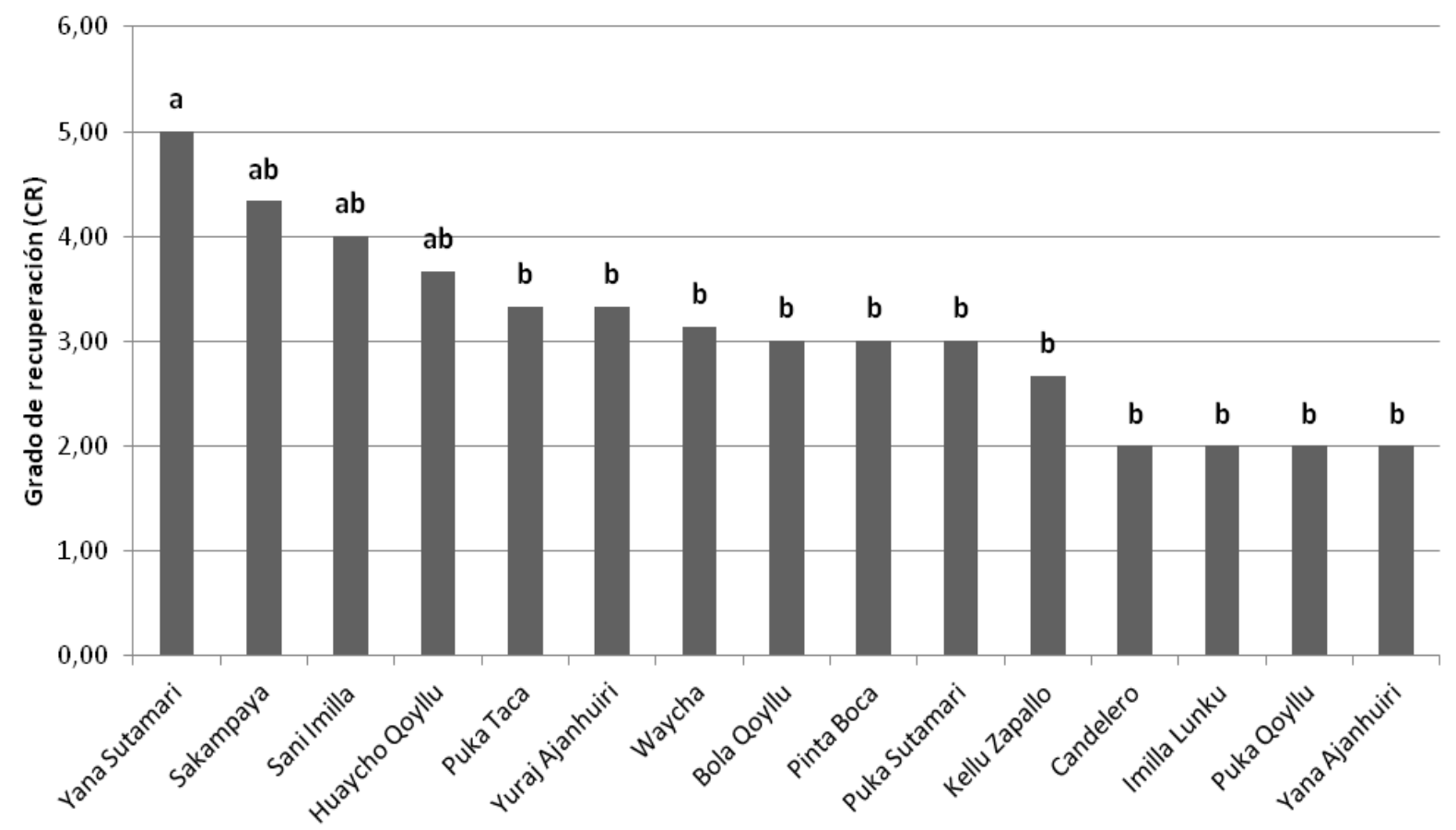

Figura 6. Respuesta de recuperación $(\mathrm{CR})$ para 15 cultivares nativos sometidos a sequia con aplicación de bioinsumos. Año 2012. Las medias con la misma letra son estadísticamente iguales entre sí $(\mathrm{P}<0,01)$.

Hubo diferencias significativas para sequia en rendimiento $(\mathrm{P}<0,01)$, siendo que el tratamiento de sequia redujo el rendimiento en $22 \%$. También se observó diferencias significativas para bioinsumo
$(\mathrm{P}<0,01)$; sin embargo, no hubo interacción bioinsumo*sequia $(\mathrm{P}=0,77)$, lo cual significa que las diferencias en rendimiento entre los tres bioinsumos fueron las mismas tanto bajo riego como 
bajo sequia (Figura 7). El rendimiento obtenido con el bioinsumo Gallinaza bajo riego fue superior a los rendimientos obtenidos con Humus bajo riego y sequia y al obtenido con Humus + Mibac bajo sequia y estadísticamente igual a los obtenidos con Gallinaza bajo sequia y Humus + Mibac bajo riego (Figura 7).

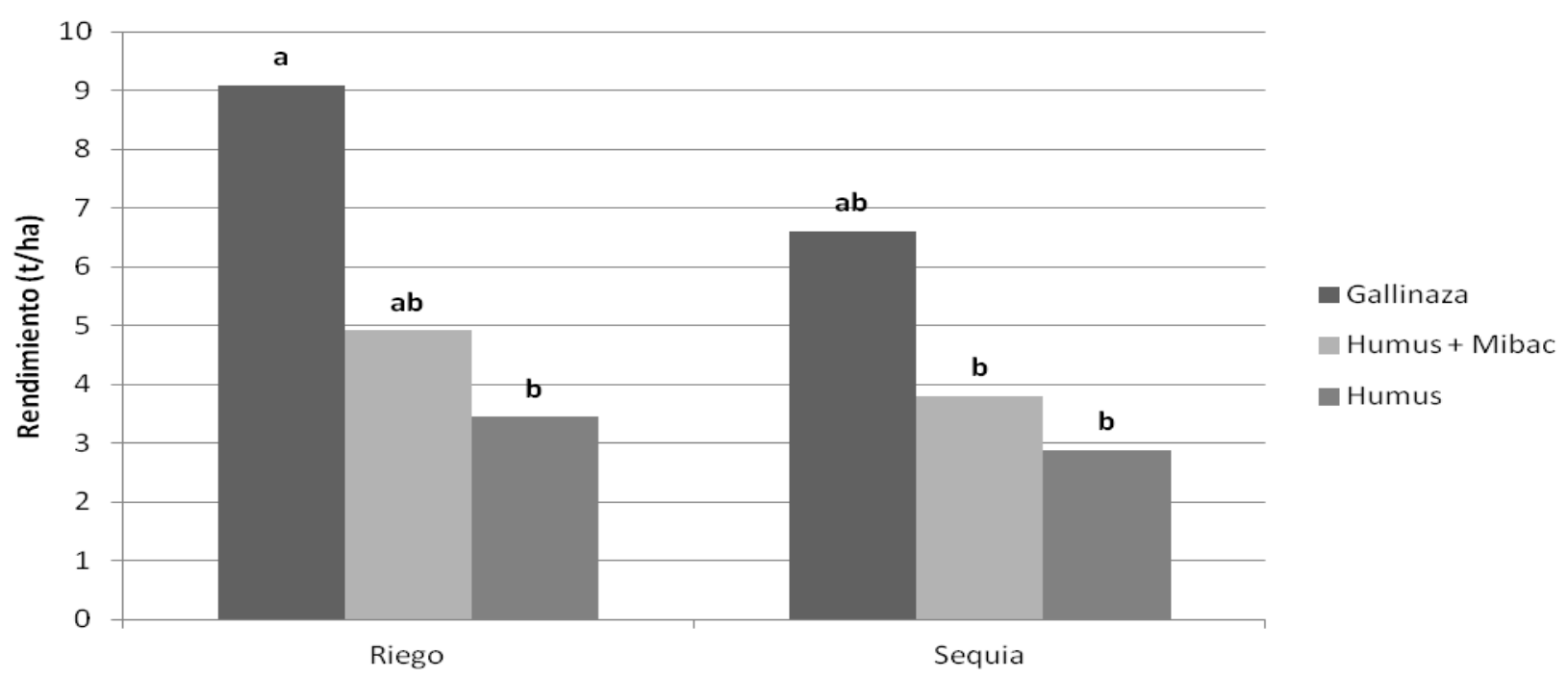

Figura 7. Respuesta en rendimiento (t.ha $\left.{ }^{-1}\right)$ de cultivares a la aplicación de tres bioinsumos aplicados bajo sequia y riego normal. Año 2012. Las medias con la misma letra son estadísticamente iguales entre sí $(\mathrm{P}<0,01)$.

Asimismo, hubo diferencias significativas para cultivar. $(\mathrm{P}<0,01)$. No se observaron interacciones para cultivar* sequia $(\mathrm{P}=0,99)$ ni para cultivar*bioinsumo $(\mathrm{P}=0,28)$. Esto significa que las diferencias en rendimiento entre los cultivares fueron las mismas con o sin sequia o con cualquiera de los tres bioinsumos (Figura 8). En la Figura 8 se compararon las medias de los tres bioinsumos para cada cultivar bajo sequia y se observó que a pesar de no existir interacción cultivar*bioinsumo, la mayoría de los cultivares obtuvieron mayor rendimiento (aunque no significativo, posiblemente debido a que las diferencias de las medias son pequeñas y no perceptibles por la prueba) con Gallinaza. Por otra parte, cuando se compararon las medias de rendimiento bajo sequia para los 15 cultivares (Figura 9) se observó que los cultivares tetraploides (Yana Sutamari, Sakampaya, Waych'a, Imilla Lunku, Puka Sutamari y Sani Imilla) obtuvieron rendimientos estadísticamente iguales entre sí. Del mismo modo, los cultivares diploides (Puka Taca, Yuraj Ajanhuiri, Kellu Zapallo, Bola Qoyllu, Huaycho Qoyllu, Puka Qoyllu, Pinta Boca, Candelero y Yana Ajanhuiri) también obtuvieron rendimientos estadísticamente iguales entre sí (Figura 9). 


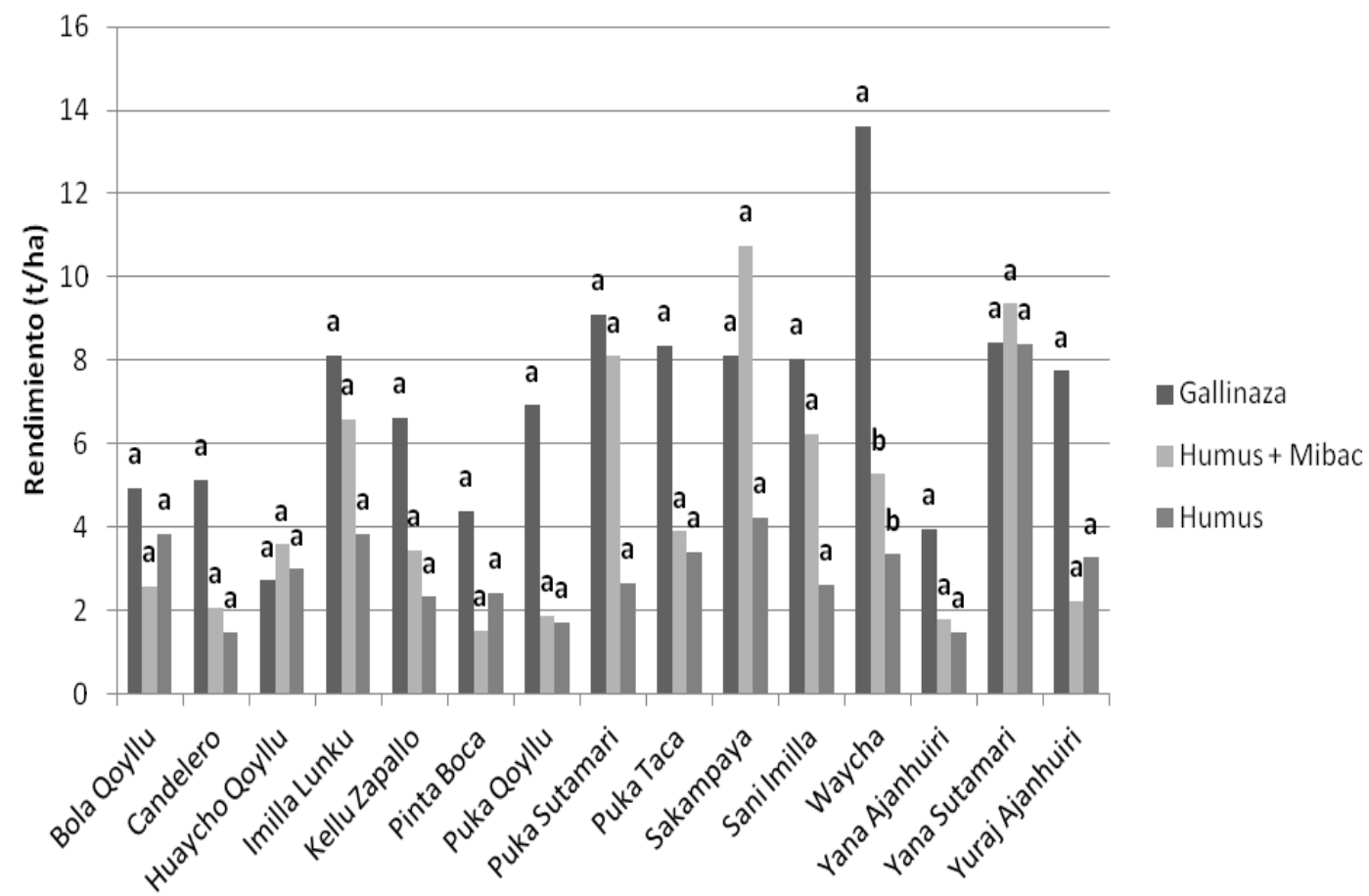

Figura 8. Respuesta de rendimiento (t.ha ${ }^{-1}$ ) de 15 cultivares de papa en los que se aplicó tres tratamientos de bioinsumos bajo sequia. Año 2012. Las medias con la misma letra son estadísticamente iguales entre sí $(\mathrm{P}<0,01)$.

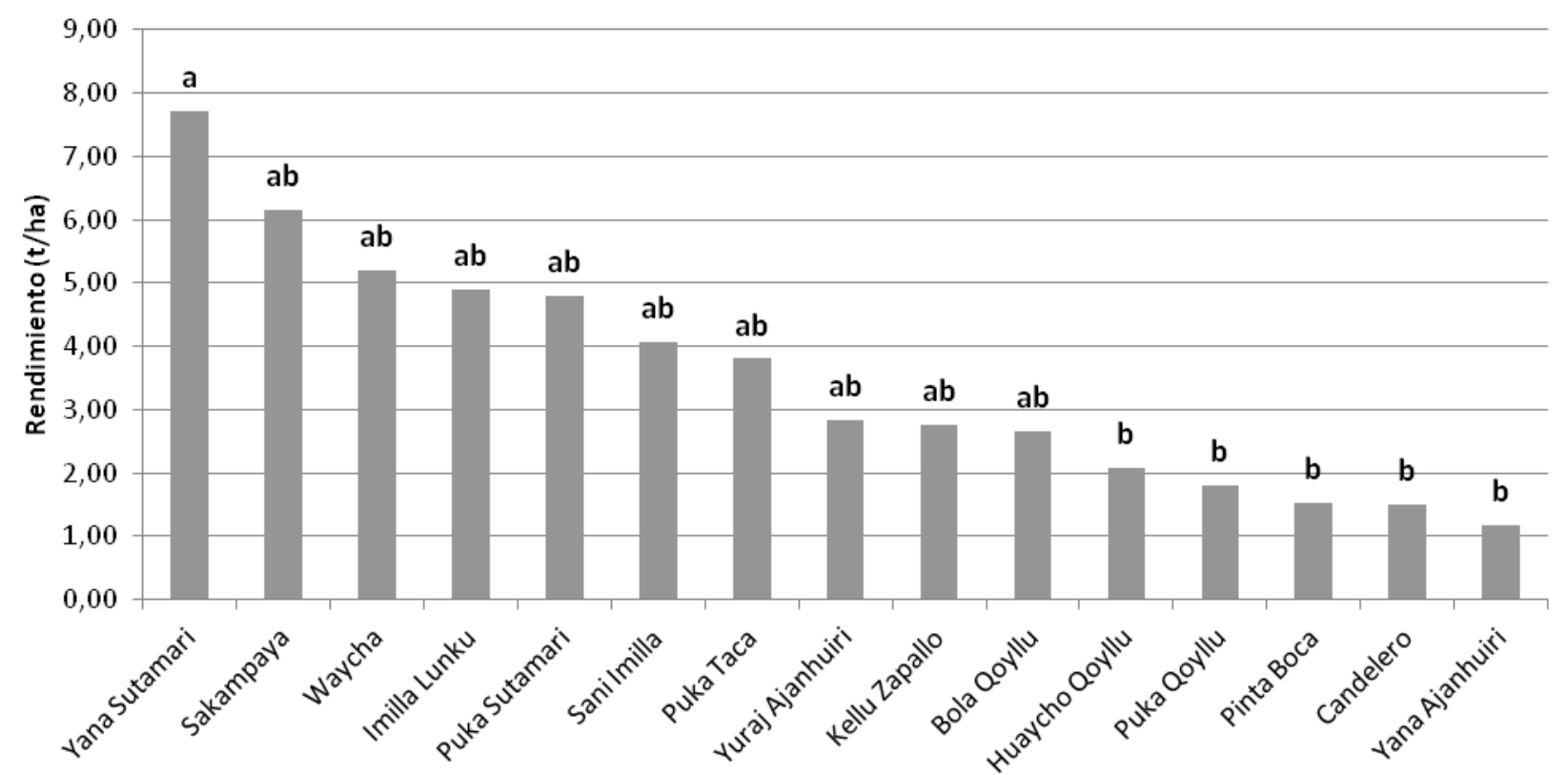

Figura 9. Respuesta de rendimiento (t.ha $\left.{ }^{-1}\right)$ de 15 cultivares de papa bajo sequía y aplicación de bioinsumos. Año 2012. Las medias con la misma letra son estadísticamente iguales entre sí $(\mathrm{P}<0,01)$.Año 2012. Las medias con la misma letra son estadísticamente iguales entre sí $(\mathrm{P}<0,01)$.

Los Coeficientes de Variación (C.V.) estuvieron entre 17 a $24 \%$ y son apropiados para este tipo de experimentos en campo.
El análisis de correlación de Pearson se realizó entre el grado de severidad, el grado de recuperación, el rendimiento y las demás variables de respuesta bajo sequia 
para cada bioinsumo. Para el bioinsumo Gallinaza (Tabla 4) se observa que existió una alta asociación negativa entre el grado de severidad y el grado de recuperación, la altura de planta y el diámetro de tallo
$(\mathrm{P}<0,01)$. El rendimiento bajo sequia con el bioinsumo Gallinaza se asoció alta y positivamente con la altura de planta, diámetro de tallo y materia seca de follaje $(\mathrm{P}<0,01)$.

Tabla 4. Correlación de Pearson entre el Grado de marchites (GM), la capacidad de recuperación $(\mathrm{CR})$, el rendimiento $\left(\mathrm{tha}^{-1}\right)$ y diez variables morfológicas, fisiológicas y componentes de rendimiento para el bioinsumo Gallinaza aplicado en 15 cultivares sometidos a sequia.

\begin{tabular}{|c|c|c|c|c|c|c|c|c|c|c|c|c|c|}
\hline & GM & CR & CC & DF & AP & DT & MSF & MSR & LR & VR & CF & NT & YT \\
\hline GM & 1 & $\overline{\mathbf{0}, 58 * *}$ & 0,28 & $-0,25$ & $\overline{0,72 * * *}$ & $\overline{\mathbf{0}}, \mathbf{8 3} * *$ & $-0,46$ & $-0,29$ & $-0,34$ & $-0,53$ & $-0,51$ & $-0,48$ & $-0,52$ \\
\hline GR & & 1 & $-0,47$ & $-0,26$ & 0,38 & 0,44 & 0,36 & 0,19 & 0,13 & 0,33 & 0,23 & 0,38 & 0,33 \\
\hline YT & & & $-0,20$ & 0,15 & $0,60 * *$ & $0,63^{* * *}$ & $0,56^{* * *}$ & 0,04 & 0,01 & 0,14 & 0,29 & 0,17 & 1 \\
\hline
\end{tabular}

Leyendas: GM - Grado de marchitez o Severidad (0: Normal, 5:muerto), CR - Capacidad de recuperación (0: no recupera, 5: Completamente recuperado), CC - Contenido de clorofila, DF - Número de días al 50\% de floración, AP -Altura de planta (cm.), DT - Diámetro de tallo (mm), MSF - Materia seca de follaje (g), MSR Materia seca de raíz (g), LR - Longitud de raíz $(\mathrm{cm}), \mathrm{VR}$ - Volumen de raíz $\left(\mathrm{cm}^{3}\right), \mathrm{CF}$ - Cobertura foliar, NT Número de tubérculos y Y - Rendimiento (t.ha $\left.{ }^{-1}\right)$, ** - Altamente significativo $(\mathrm{P}<0,01)$, * Significativo $(\mathrm{P}<0,05), \mathrm{ns}-$ no significativo, Números en negrilla son las correlaciones altas y significativas.

El análisis de correlación para el efecto del bioinsumo Humus + Mibac (Tabla 5) bajo sequia mostró que hubo una alta asociación positiva entre el grado de recuperación y el rendimiento $(\mathrm{P}<0,01)$. El rendimiento bajo sequia con el bioinsumo Humus + Mibac se asoció alta y positivamente con el grado de recuperación, la altura de planta y el diámetro de tallo $(\mathrm{P}<0,01)$. 
Tabla 5. Correlación de Pearson entre el Grado de marchites (GM), la capacidad de recuperación (CR), el rendimiento $\left({\left.\mathrm{t} . h \mathrm{~h}^{-1}\right)}\right.$ y diez variables morfológicas, fisiológicas y componentes de rendimiento para el bioinsumo Humus + Mibac aplicado en 15 cultivares sometidos a sequia.

\begin{tabular}{|c|c|c|c|c|c|c|c|c|c|c|c|c|c|}
\hline & GM & GR & $\mathrm{CC}$ & DF & AP & DT & MSF & MSR & LR & VR & YT & $\mathrm{CF}$ & NT \\
\hline GM & 1 & $-0,42$ & $-0,40$ & 0,02 & $-0,29$ & $-0,44$ & $-0,39$ & $-0,09$ & $-0,16$ & $-0,003$ & $-0,51$ & $-0,25$ & $-0,21$ \\
\hline GR & & 1 & 0,23 & $-0,04$ & 0,55 & 0,57 & 0,48 & $-0,11$ & 0,27 & 0,32 & $0,65^{* *}$ & 0,54 & 0,37 \\
\hline YT & & & 0,55 & $-0,08$ & $0,60 * *$ & $0,62 * *$ & 0,33 & 0,13 & 0,29 & 0,12 & 1 & 0,53 & 0,48 \\
\hline
\end{tabular}

Leyendas: GM - Grado de marchitez o Severidad (0: Normal, 5:muerto), CR - Capacidad de recuperación (0: no recupera, 5: Completamente recuperado), CC - Contenido de clorofila, DF - Número de días al 50\% de floración, AP -Altura de planta (cm.), DT - Diámetro de tallo $(\mathrm{mm})$, MSF - Materia seca de follaje (g), MSR Materia seca de raíz (g), LR - Longitud de raíz $(\mathrm{cm}), \mathrm{VR}$ - Volumen de raíz $\left(\mathrm{cm}^{3}\right), \mathrm{CF}$ - Cobertura foliar, NT Número de tubérculos y Y - Rendimiento (t.ha $\left.{ }^{-1}\right)$, ** - Altamente significativo $(\mathrm{P}<0,01)$, * Significativo $(\mathrm{P}<0,05), \mathrm{ns}-$ no significativo, Números en negrilla son las correlaciones altas y significativas.

El análisis de correlación para el efecto del Humus bajo sequia (Tabla 6) mostró una alta asociación negativa entre el grado de severidad, el contenido de clorofila y el diámetro de tallo $(\mathrm{P}<0,01)$. El grado de recuperación bajo sequia con Humus se asoció alta y positivamente con la materia seca de follaje y el rendimiento $(\mathrm{P}<0,01)$. El rendimiento bajo sequia con Humus se asoció alta y positivamente con el grado de recuperación, el diámetro de tallo y la materia seca de follaje $(\mathrm{P}<0,01)$. Asimismo, el contenido de clorofila se asoció con el diámetro de tallo.

Tabla 6. Correlación de Pearson entre el Grado de marchites (GM), la capacidad de recuperación (CR), el rendimiento $\left(\mathrm{t} \mathrm{ha}^{-1}\right)$ y diez variables morfológicas, fisiológicas y componentes de rendimiento para el bioinsumo Humus aplicado en 15 cultivares sometidos a sequia.

\begin{tabular}{|c|c|c|c|c|c|c|c|c|c|c|c|c|c|}
\hline & GM & GR & $\mathrm{CC}$ & DF & AP & DT & MSF & MSR & LR & VR & YT & CF & NT \\
\hline GM & 1 & $-0,29$ & $\overline{\mathbf{0}, 79 * *}$ & $-0,26$ & $-0,42$ & $\overline{\mathbf{0}, 73 * *}$ & $-0,43$ & $-0,35$ & $-0,34$ & 0,03 & $-0,54$ & $-0,04$ & $-0,23$ \\
\hline GR & & 1 & 0,06 & 0,49 & 0,24 & 0,29 & $0,63^{* * *}$ & 0,42 & 0,07 & 0,31 & $0,76^{* * *}$ & 0,38 & 0,18 \\
\hline $\mathrm{CC}$ & & & 1 & 0,06 & 0,34 & $0,60 * *$ & 0,18 & 0,30 & 0,41 & $-0,13$ & 0,23 & $-0,09$ & 0,28 \\
\hline YT & & & & 0,40 & 0,46 & $\mathbf{0 , 5 8} * *$ & $0,77^{* *}$ & 0,54 & 0,26 & 0,14 & 1 & 0,45 & 0,27 \\
\hline
\end{tabular}

Leyendas: GM - Grado de marchitez o Severidad (0: Normal, 5:muerto), CR - Capacidad de recuperación (0: no recupera, 5: Completamente recuperado), CC - Contenido de clorofila, DF - Número de días al 50\% de floración, AP -Altura de planta (cm.), DT - Diámetro de tallo (mm), MSF - Materia seca de follaje (g), MSR Materia seca de raíz (g), LR - Longitud de raíz (cm), VR - Volumen de raíz $\left(\mathrm{cm}^{3}\right), \mathrm{CF}$ - Cobertura foliar, NT Número de tubérculos y $\mathrm{Y}$ - Rendimiento (t.h $\left.{ }^{-1}\right)$, ** - Altamente significativo $(\mathrm{P}<0,01)$, * - Significativo $(\mathrm{P}<0,05)$, ns - no significativo, Números en negrilla son las correlaciones altas y significativas.

\section{Discusión}

El contenido de humedad en nuestro ensayo fue claramente superior bajo riego que bajo sequia. Esto indica que la sequia redujo el contenido de humedad hasta en un $72 \%$ al final de los 30 días de sequia en pretuberización.

En nuestro estudio observamos que con el bionsumo Gallinaza se obtuvieron la menor severidad y la mayor recuperación. Por otra parte, el rendimiento con Gallinaza bajo sequia fue superior (aunque no significativamente) en un $42 \%$ al rendimiento bajo sequia con Humus + Mibac y superior en un 56\% (aunque no significativamente) al rendimiento con Humus. Esto se debería en parte, a los efectos positivos que tiene el estiércol Gallinaza en las propiedades del suelo ya 
que estabiliza la estructura del suelo y por tanto se reduce la densidad aparente del suelo, se incrementan la porosidad, la tasa de infiltración y la retención de agua. El aumento de la porosidad y el contenido de humedad en el suelo incrementan a su vez el crecimiento de la raíz y la absorción de agua y nutrientes. Además, los nutrientes liberados por la Gallinaza tienen un efecto directo en el crecimiento y el rendimiento (Agbede et al., 2008).

La calidad y la composición química de la materia orgánica también determinan su efecto en la estructura del suelo y la agregación de las partículas. Algunos tipos de materia orgánica (el Humus y el Humus + Mibac en nuestro caso) sufren una rápida descomposición que a su vez genera un rápido incremento de la estabilidad de los agregados del suelo, la cual se refleja en la liberación de partículas que promueven la agregación del suelo. Cuando estos tipos de materia orgánica continúan con su proceso de descomposición, se pierden del sistema resultando en una reducción de la estabilidad de los agregados del suelo. El lento suministro de las partículas que promueven la agregación de algunos tipos de materia orgánica (Gallinaza) resulta en un incremento más lento pero sostenible de los agregados del suelo. Esto significa que una continúa provisión de estas partículas es necesaria para un incremento continúo de la estabilidad de los agregados del suelo (Bot y Benites, 2005). Debido a la rápida descomposición del humus en nuestro experimento sería necesario agregar una segunda dosis en el aporque para que pueda tener un mejor efecto sobre la sequia. Asimismo, el Micobac no tuvo el efecto esperado ya que necesita de estiércol $u$ otra materia orgánica descompuesta, para favorecer el establecimiento, multiplicación y efecto de los microorganismos (Ortuño et al., 2011).
El cultivar más resistente con el uso de Gallinaza fue Sani Imilla. Este cultivar fue susceptible a sequia en un ensayo previo en invernadero sin el uso de Gallinaza ( $\sin$ publicar). Por tanto, este cultivar tendría una excelente respuesta a la sequia en campo bajo el uso del bioinsumo Gallinaza.

Yana Sutamari, entre las tetraploides y Puka Taca, entre las diploides obtuvieron la menor severidad, el mayor grado de recuperación y el mejor rendimiento bajo sequia. Estos cultivares obtuvieron asimismo los mayores grados de resistencia y recuperación en un ensayo posterior para resistencia a sequia ( $\sin$ publicar).

No hubo interacción bioinsumo*cultivar para severidad, para recuperación ni para rendimiento. Esto significa que el mejor bioinsumo (gallinaza) fue el mejor para cualquiera de los 15 cultivares tanto para reducir la severidad de daño como para incrementar la recuperación y el rendimiento después de un mes de sequia en la etapa de pre-tuberización. Esto reporta una ventaja ya que se requiere aplicar un solo bioinsumo a todos estos cultivares para reducir el daño por sequia en pre-tuberización.

En un estudio posterior (sin publicar) se aplicó el mejor bioinsumo de presente estudio (gallinaza) en dos combinaciones junto a un testigo absoluto en los dos cultivares nativos más comerciales del presente estudio (Waych'a y Pinta Boca) bajo un tratamiento de sequia de un mes de suspensión de riego en pre tuberización. Las combinaciones de bioinsumos fueron: gallinaza y gallinaza + micobac. En dicho trabajo observamos que el uso de bioinsumos no influyó significativamente en la respuesta de estas dos variedades al estrés hídrico. Esto podría deberse a que en dicho estudio la sequia fue mas severa. Esto significa que podría existir interacción entre el grado de sequia y el 
efecto de los bioinsumos. También se observó que para ambos cultivares la combinación gallinaza + micobac obtuvo mayores rendimientos aunque no significativos que la gallinaza. Finalmente, la ausencia de bioinsumo (testigo absoluto) redujo los rendimientos al máximo tanto en riego como bajo sequia. Es más, el rendimiento del testigo bajo riego fue inferior al obtenido con gallinaza bajo sequia. Esto quiere decir que la falta de cualquier bioinsumo redujo más el rendimiento que la sequia. Esto a su vez indica la poca capacidad de retención de agua en estos suelos y que explica los efectos devastadores de la sequia en los cultivos en estas regiones.

En un trabajo previo sobre resistencia al estrés hídrico por sequía en cultivares nativos bajo condiciones de invernadero, Gabriel et al. (2011) encontraron que el grado de marchitez (GM) se asoció muy alta y negativamente con la capacidad de recuperación (CR), esto indicaría que cuanto mayor fue la severidad, menor fue el grado de recuperación. Es lógico suponer que cuanta más severidad alcanzó un cultivar le fue más difícil recuperarse. En nuestro caso, también observamos una asociación alta y negativa entre GM y CR con el uso del bioinsumo Gallinaza. Esto significa que estos 15 cultivares recuperan mejor después de una sequia de 30 días cuando tienen menor severidad y se aplica Gallinaza. No se observó esta relación con ninguno de los otros bioinsumos.

Para los tres bioinsumos, los cultivares más vigorosos (mayor diámetro de tallo).

fueron más resistentes y obtuvieron mayores rendimientos bajo sequia. Esta es una relación importante y el mayor diámetro de tallo podría servir como variable de selección para resistencia a sequia. El grosor de los internudos en trigo también es considerado como un rasgo adaptado a la sequia ya que permite almacenar fructanos para el llenado de grano en periodos de sequia (Ribaut y Poland, 2000).
También se observó que con el bioinsumo Humus las plantas con menor contenido de clorofila fueron mas susceptibles y las con mayor contenido de clorofila fueron más resistentes. Esto significa que la producción de clorofila fue reducida en las plantas cuando el grado de severidad fue mayor. En los otros dos bioinsumos no se observó un efecto en el contenido de clorofila, esto podría ser porque el grado de severidad fue menor. Esto concuerda con lo encontrado por Anithakumari et al. (2012) quienes observaron una disminución sustancial del contenido de clorofila a medida que la severidad incrementaba. Asimismo, encontraron que los QTLs para contenido de clorofila colocalizaban con los QTLs para altura de planta y peso de materia seca, lo que demuestra que el mayor contenido de clorofila estaría asociado con un mayor vigor de la planta. En nuestro caso, el mayor contenido de clorofila estuvo asociado con un mayor diámetro de tallo cuando se uso el bioinsumo Humus. Esto también significa un mayor vigor de planta.

\section{Conflictos de intereses}

Los autores declaran no tener conflictos con la publicación este trabajo de investigación.

\section{Agradecimientos}

Se agradece el apoyo económico del Fondo Regional de Tecnología Agropecuaria (FONTAGRO).

\section{Referencias citadas}

Agbede T.M.; Ojeniyi S.O.; Adeyemo A.J. 2008. Effect of poultry manure on soil physical and chemical properties, growth and grain yield of sorghum in southwest, Nigeria. American-Eurasian J. Sust. Agri. 2: 72-77.

Anithakumari, A.M.; Karaba, N.; Nataraja, N.; Richard, G.F.; Visser, F.; Gerard van der Linden C. 2012. Genetic dissection of drought tolerance and recovery potential by quantitative trait locus mapping of a 
diploid potato population. Mol. Breed. 30 (3): 1413-1429.

Angulo, A.; Siles, M.; Ríos, R.; Gabriel, J. 2009. Caracterización de 118 accesiones de arveja (Pisum sativum L.) del Banco de Germoplasma del Centro de Investigaciones Fitoecogenéticas de Pirumani para resistencia a sequía. Revista de Agricultura 42 (60): 25-31.

Avilés, M.; Borrero, C.; Trillas M.I. 2011. Compost supresivos a las enfermedades de las plantas. Revista Ae (3): 6-8.

Bot, A.; Benites, J. 2005. The importance of soil organic matter. FAO Soils Bulletin 80. FAO, Rome. 78 p.

Blum, A. 1993. Selection for sustained production in water deficit environments. Crop Sci. I: 343-347.

Cadima, X.; Gonzales, R.; Almanza, J.; Garcia, W.; Terrazas, F. (eds.). 2004. Catálogo de variedades locales de papa y oca de la zona de Candelaria. Serie: Conservación y uso de la biodiversidad de raíces y tubérculos andinos: Una década de investigación para el desarrollo (19932003), No. 5. PROINPA, Municipio de Colomi, CIP, COSUDE. Cochabamba, Bolivia. $112 \mathrm{p}$.

Ceccarelli, S. 1984. Plant responses to water stress. Gen. Agraria 38:43-74.

Estrada, N. 2000. La Biodiversidad en el Mejoramiento Genético de la papa. Bill Hardy, Emma Martinez (Ed.) La Paz, Bolivia. 372 p.

Ellisseche, D. 2000. La patata. Páginas 67 - 94 in Tirilly Y., Marcel B. C (Eds.): Tecnología de las hortalizas. Trad. por Pedro M. Aparicio Tejo y Carmen Lansfus Arrien. Ed. Acribia S.A. Zaragoza, España.

FAO. 2012. (Faostat) Food and Agriculture Organization of the United Nations Statistical Databases (FAO) (http://faostat.fao.org): $\quad$ Consulta: 16/09/2013.
Egúsquiza, R. 2000. La Papa: producción, transformación, comercilización. Universidad Agraria La Molina, Lima, Perú. 192 p.

Ekanayake, I.J. 1993. Estudios sobre el estrés hídrico por sequia y necesidades de riego de la papa. Lima Perú, Centro Internacional de la Papa (CIP). 38 p.

Ferrari, D.M.; Pozzolo, O.R.; Ferrari, H.J. 2007. CobCal v1.0: Guía rápida. INTA, Argentina. 8 p.

Gabriel, J.; Porco, O.; Angulo, A.; Magne, J.; La Torre J.; Mamani P. 2011. Genetic resistance to water stress by drought in potato varieties (Solanum tuberosum L.) unde greenhouse conditions. Revista Latinoamericana de la Papa 16 (2): 173 208.

Gabriel, J. 2010. Documento marco: Estrategias y perspectivas del mejoramiento genético de papa (Solanum tuberosum L.) en Bolivia. Fundación PROINPA, Cochabamba, Bolivia. 60 p.

Gabriel, J.; Pereira, R.; Gandarillas, A. 2011. Catálogo de nuevas variedades de papa en Bolivia. Fundación PROINPA, Cochabamba, Bolivia. 55 p.

Gajalakshmi, S.; Abbasi, S.A. 2004 Eathworms and vermicomposting. Indian J. Biotech. 3: 486-494.

Gonzales, A. 2009. Aplicación del medidor portátil de clorofila en programas de mejora de trigo y cebada. Agroecología 4: 111-116.

Instituto Nacional de Estadística de Bolivia (INE). 2013. Bolivia: Eventos adversos de origen natural reportados, según tipo de evento, 2002-2012. http://www.ine.gov.bo/indice/visualizador. aspx?ah=PC80601.HTM. Consulta: Septiembre - 2013.

Iriarte, V.; Condori, B.; Parapo, D.; Acuña, D. 2009. Catálogo etnobotánico de papas 
nativas del Altiplano Norte de La PazBolivia. Cochabamba, Bolivia. 142 p.

Mamani, P. 2000. Effet de la secheresse sur six varietés de ponme de terre dans les andes boliviennes. Tesis M.Sc., Universite Catholique de Louvain, Faculte des Sciences Agronomiques, Bélgica. 43 p.

Martinez - Garza, A. 1988. Diseños experimentales: Métodos y elementos de teoría. Trillas, México D. F., Mexico. 756 p.

Miller, D.E.; Marti, M.W. 1987. The effect of irrigation regime and subsofling on yield and quality of three potato cultivars. Am. Potato J. 64: 17-26.

Montecinos, E. 2011. Bacterias promotoras del crecimiento de las plantas, Ae. Agricultura y Ganaderia Ecológica (3): 9-11.

Ortuño, N.; Navia, O.; Medrano, A.; Rojas, K.; Torrico, L. 2010. Desarrollo de Bioinsumos: Un Aporte Importante a la Soberanía Alimentaria de Bolivia. Revista de Agricultura (47): 31-35.

Ortuño, N.; Navia, O.; Meneces, E.; Barja, D.; Villca, S.; Plata, G.; Claros, M.; Gutiérrez, C.; Arandia, W.; Crespo, L. 2011. Catalogo de Bioinsumos para mejorar la producción de los cultivos ecológicos y convencionales. PROINPABIOTOP, Cochabamba, Bolivia. p. 13-14.

Radulovich, R. 2009. Método gravimétrico para determinar in situ la humedad volumétrica del suelo. Agronomía Costarricense 33 (1): 121-124.

Ribaut, J.M.; Poland, D. (eds). 2000. Molecular approaches for the genetic improvement of cereals for stable production in water-limited environments. A strategic planning workshop held at CIMMYT, El Batan, Mexico, 21-25 June 1999. Mexico DF: CIMMYT.
Rojas, K.; Ortuño, N. 2007. Evaluación de micorrizas arbusculares en interacción con abonos orgánicos como coadyuvantes del crecimiento en la producción hortícola del Valle Alto de Cochabamba, Bolivia. Rev. ActaNova 3(4): 697-718.

SAS Institute Inc. 2004. SAS/STAT Users Guide, Version 9.2, Fourth Edition, Vol. 2, SAS Institute Inc., Cary, N.C.

Siles, M. 2005. Diseño de bloques incompletos con una sola repetición en la evaluación preliminar de material avanzado en programas de mejoramiento genético de cultivos. Revista de Agricultura 34: 39-45.

Terrazas, F.; Cadima, X.; García, R.; Zeballos, J. 2008. Catálogo etnobotánico de papas nativas. Tradición y cultura de los Ayllus del Norte Potosí y Oruro. Ricerca \& Cooperazione, Unión Europea, Centro de Apoyo a Desarrollo, GTZ, Fundación PROINPA, MDRyMA. Cochabamba Bolivia. 189 p.

Torrez, W.; Foronda, H. 2008. Producción de semilla de papa dentro del Sistema Nacional de Certificación de Semillas. Revista de Agricultura 43 (60): 3-9.

Thiele, G.; Hareau, G.; Suarez, V.; Chujoy, E.; Bonierbale, M.; Maldonado, L. 2008. Varietal change in potatoes in developing countries and the contribution of the International Potato Center (IPC): 19722007. ICP, Lima, Peru. Working Paper 2008-6. 46 p.

Warren, S.L.; Fonteno, W.C. 1993. Changes in physical and chemical properties of a loamy sand soil when amended with composted poultry litter. J. Envir. Horti. 11, 186-190.

Zeballos, H.; Balderrama, F.; Condori, B.; Blajos, J. 2009. Economía de la papa en Bolivia (1998-2007). Fundación PROINPA, Cochabamba, Bolivia. 129 p. 